Çukurova Üniversitesi Mühendislik Mimarlık Fakültesi Dergisi, 31(ÖS 1), ss. ÖS 133-ÖS 141, Ağustos 2016

Çukurova University Journal of the Faculty of Engineering and Architecture, 31(ÖS 1), pp. SI 133-SI 141, August 2016

\title{
Orbital Tig Kaynak Yöntemiyle Kaynak Edilmiş Dubleks Paslanmaz Çeliklerin Mekanik, Metalurjik ve Korozyon Özellikleri
}

\author{
Umut SÖNMEZ $^{* 1}$, Niyazi ÇAVUŞOĞLU ${ }^{1}$, Vural CEYHUN ${ }^{1}$ \\ ${ }^{1}$ Ege Üniversitesi, Mühendislik Fakültesi, Makine Mühendisliği Bölümü, İzmir
}

Geliş tarihi: 14.02.2016 Kabul tarihi:30.03.2016

\begin{abstract}
Özet
Bu çalışmada özellikle kimya, petrol ve doğalgaz, gemi inşa, ilaç, gıda sanayi gibi alanlarda yaygın olarak kullanılan dubleks paslanmaz çelik boruların orbital TIG kaynağı konusu incelenmiştir. $150 \mathrm{~mm}$ uzunluğunda, $1 \mathrm{~mm}$ et kalınlığı ve $25 \mathrm{~mm}$ çapındaki dubleks paslanmaz çelik borular (UNS 31803 ve EN 1.4462 ile tanımlı) üç farklı kaynak parametresi kullanılarak koruyucu ve kök koruyucu gaz olarak saf argon gazı altında alın alına kaynak edilmiştir. Kaynak edilen numunelere çekme, taneler arası ve oyuk korozyon testleri (EN ISO 3651-1, ASTM G48-11), SEM-EDX analizleri ve mikroyapı incelemeleri yapılmıştır. Tüm numuneler IEB'den kırılmıştır. $\mathrm{C}_{2} \mathrm{~N}$, intermetalik fazlar ve karbür oluşumlarına rastlanılmamıştır. Tüm kaynaklı numuneler taneler arası ve oyuk korozyonu için yeterli dayanımı sağlamıştır.
\end{abstract}

Anahtar Kelimeler: Dubleks Paslanmaz Çelik, Orbital Kaynak, Taneler Arası Korozyon, Oyuk korozyonu

The Mechanical, Metallurgical and Corrosion Properties of Duplex Stainless Steel Pipes Welded by Orbital GTAW

\begin{abstract}
In this study, orbital GTAW welding of duplex stainless steel pipes which especially being used in areas such as chemistry, oil and gas, shipbuilding, medicine, food industry, is investigated. Duplex stainless steel pipe specimens (defined by UNS 31803 and EN 1.4462) which have $150 \mathrm{~mm}$ long, $1 \mathrm{~mm}$ thickness and $25 \mathrm{~mm}$ diameter, were butt-welded with three different welding parameters using pure argon gas as shielding gas. Intergranular and pitting corrosion tests (EN ISO 3651-1, ASTM G48-11), tensile test, SEM-EDX analysis and microstructure analysis were performed on welded samples. All specimens were fractured from HAZ. $\mathrm{C}_{2} \mathrm{~N}$ precipitates, intermetallic phases and carbide formation were not found. All welded specimens performed good intergranular and pitting corrosion properties.
\end{abstract}

Keywords: Duplex stainless steel, Orbital welding, Intergranular corrosion, Pitting corrosion

\footnotetext{
*Sorumlu yazar (Corresponding author) : Umut SÖNMEZ, Ege Üniversitesi, Mühendislik Fakültesi, Makine Mühendisliği Bölümü, İzmir. usonmez1979@gmail.com
} 


\section{GíRiş}

Dubleks paslanmaz çelikler latince'de iki parçadan oluşan anlamına gelir. Mikro yapılarında hem ferrit hem de ostenit fazlarını bir arada içeren paslanmaz çeliklerdir. Dubleks paslanmaz çelikler, normal oda sıcaklığında genelde eşit miktarda \%50 ostenit ve $\% 50$ ferrit içerirler. Mikro yapıdaki ferrit/ostenit dengesi, mekanik özellikler ve korozyon davranışı üzerinde çok önemli etkiye sahiptir. Dubleks paslanmaz çelikler, ostenitik paslanmaz çeliklerle karşılaştırıldığında gerilmeli korozyon çatlağı ve oyuk korozyonuna karş1 yüksek direnç ve yüksek mekanik dayanıma sahiptir. $\mathrm{Bu}$ nedenle nükleer tesisler, petrol ve doğalgaz boru hatları, kimyasal tesisler ve denizcilik alanlarında yaygın olarak kullanılmaktadırlar.

Dubleks malzemelerin karmaşık alaşım içerikleri nedeniyle $1000^{\circ} \mathrm{C}$ altında birincil ve ikincil fazların (krom nitrür, krom karbür, ikincil ostenit ve intermetalik fazlar) oluşumu beklenmelidir. Dubleks paslanmaz çeliklere uygulanan 1sıl işlemlerde işlem sıcaklığı ve soğuma şartları, birincil ve ikincil fazlar üzerinde önemlidir [1]. Bu malzemelere uygulanan isıl işlemler sırasında oluşan ferrit-ostenit oranına, tane sınırlarında çöken intermetalik fazlara dikkat edilmelidir [2]. Oluşan intermetalik fazlardan en yaygın görülen $\sigma$ (sigma) ve chi fazları süneklik, tokluk ve korozyon dayanım özellikleri üzerinde olumsuz etkiye sahiptir [3]. Kromca zengin nitrürler soğuma esnasında ferrit tane sınırlarında aşırı doygunluk nedeniyle oluşur [4]. Düşük sicaklık fazlarının meydana getireceği reaksiyonlar dubleks paslanmaz çelik kullanımını yaklaşık $280^{\circ} \mathrm{C}$ ile sinırlamaktadır.

Dubleks paslanmaz çeliklerin kaynak kabiliyeti genellikle ferritik paslanmaz çeliklerden daha iyi, fakat ostenitik paslanmaz çeliklerden daha kötüdür. Kaynak metalinde ferrit/ostenit dengesinin sağlanması gerekmektedir [5]. Isıdan etkilenmiş bölgede ferrit miktarının artması beklenmelidir. KM ve IEB mikroyapısı $\mathrm{Cr} / \mathrm{Ni}$ eş değeri ile birlikte kaynak esnasında malzemeye verilen ısı girdisine bağlıdır. KM ve IEB de yeterli miktarda ostenit oluşumunu sağlayacak 1sı girdisi uygulanmalıdır. Bu açıdan, çok düşük ısı girdisi ve buna bağlı olarak hızlı soğumalardan kaçınılmalıdır. Çok yüksek soğuma hızlarında yüksek ferrit miktarı, nitrür çökelmeleri ve sonuçta düşük tokluk ve düşük korozyon direnci ile karşılaşılır. Dubleks paslanmaz çeliklerin kaynağ1 alaşım içeriklerine bağlı olarak kontrollü bir 1sı girdisi ile yapılmalıdır [6].

Orbital kaynak yöntemi özellikle boruların yüksek kaliteli kaynağında TIG kaynağı ile birlikte tercih edilmektedir. Orbital denmesinin sebebi, kaynak edilecek boruların dairesel olarak hareket eden başlık içerisinde yer alan elektrot ve iş parçası arasında oluşan ark ile kaynak edilmesi nedeniyledir [7,8]. Orbital kaynağı kaynak akımı, ark uzunluğu, ilerleme hızı gibi kaynak parametrelerini ayarlanabilir ve tekrar edilebilir hale getirdiğinden boruların birleştirilmelerinde kaliteli, tutarlı ve sürekli olarak aynı tip kaynakların elde edilmesine sağlar $[9,10]$. Bununla birlikte yüksek üretim hızı, düşük çarpılma, 1S1 girdisinin kontrolüyle daha dar IEB oluşması yöntemin diğer avantajları arasında sayılabilir $[11,12]$.

Orbital kaynak yönteminde kaynak edilecek dairesel alan, sektörlere bölünmektedir. Genellikle 4 sektöre bölünerek kaynak işlemi yapılır. Boruların kaynağında aynı anda çok farklı pozisyonlar söz konusudur. Bu nedenle ergiyen ve katılaşan kaynak metalinin kontrolü önemlidir ve darbeli akım kullanılması zorunludur [13].

\section{DENEYSEL ÇALIŞMALAR}

Yapılan çalışmada, $150 \mathrm{~mm}$ uzunluğa, $1 \mathrm{~mm}$ et kalınlığına sahip ve $25 \mathrm{~mm}$ çapında dubleks paslanmaz çelik borular (UNS 31803 ve EN 1.4462) kullanılmıştır. Deneylerde kullanılan paslanmaz çelik malzemenin kimyasal bileşimi Çizelge 1'de gösterilmiştir.

Kaynak işlemleri orbital TİG kaynak makinası kullanılarak, saf argon gaz ortamında alın alına bağlantı tipinde gerçekleştirilmiştir. Kaynaklı birleştirmenin özelliklerine etki edecek kaynak parametreleri; koruyucu gaz debisi $\left(\mathrm{m}^{3} / \mathrm{s}\right)$, kök koruyucu gaz debisi $\left(\mathrm{m}^{3} / \mathrm{s}\right)$, son süpürme zamanı 
(s), ilerleme hızı (mm/dk), yüksek akım (A), düșük akım (A), yüksek-düşük akım zamanı (s) olarak belirlenmiştir. $\mathrm{Bu}$ parametrelere bağl1 olarak kaynak denemelerinde iki farklı elektrot kullanılmıştır; WL-20 (\%2 seryum içeren, $30^{\circ}$ uç geometrisine sahip elektrot) ve WT-40 elektrot (\%3,80-4.20 toryum içeren, $30^{\circ}$ uç geometrisi sahip elektrot). Kaynak parametreleri ile WL ve WT elektrot isimleri birleştirilerek numuneler isimlendirilmiştir. Kaynak işlemlerinin her aşamasında kaynak voltajı $20 \mathrm{~V}$ olarak alınmıştır. Çizelge 2'de kaynak parametre değerleri çizelge halinde gösterilmiştir.

Çizelge 1. Ana malzemenin kimyasal bileşim oranlar1

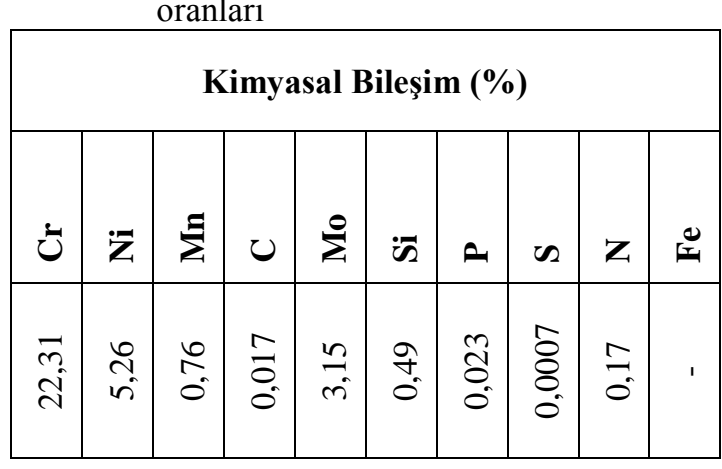

Literatür incelemeleri sonucunda ince et kalınlığına sahip dubleks paslanmaz çeliklerin kaynak işlemlerinde, $0.1 \mathrm{~kJ} / \mathrm{mm}$ 1sı girdisinin kaynak metalinde yüksek miktarda ferrit içeriğine neden olduğu görülmüştür. Buradan hareketle uygun 1S1 girdisinin belirlenebilmesi için çeşitli denemeler yapılmıştır. $0.2 \mathrm{~kJ} / \mathrm{mm}$ 1sı girdisinin nüfuziyet eksikliğine neden olduğu $0.40 \mathrm{~kJ} / \mathrm{mm}$ 1s1 girdisi değerleri üzerine çıkıldığında ana malzemenin ergiyip delindiği belirlenmiştir. Farklı kaynak pozisyonlarının, kaynak işlemi süresince borunun bazı kısımlarında yetersiz 1sı girdisine sebep olmasından dolayı kaynak bölgesi 4 ayrı sektöre bölünmüştür.

Kaynak edilen numunelere çekme, sertlik, taneler arası korozyon testi (EN ISO 3651-1) ve oyuk korozyon testi (ASTM G48-11) uygulanmıştır. Ayrıca, SEM-EDX analizleri ile mikro yap1 incelemeleri gerçekleştirilmiştir.
Çizelge 2. Kaynak parametrelerinin gösterimi

\begin{tabular}{|c|c|c|c|c|}
\hline & \begin{tabular}{|l|} 
Kaynak \\
parametreleri
\end{tabular} & 1. & 2. & 3. \\
\hline & Elektrot tipi & WL/WT & WL/WT & WL/WT \\
\hline & $\begin{array}{l}\text { Koruyucu gaz } \\
\text { debisi }\left(\mathrm{m}^{3} / \mathrm{s}\right)\end{array}$ & 25 & 30 & 32 \\
\hline & $\begin{array}{l}\text { Kök koruyucu } \\
\text { gaz debisi }\left(\mathrm{m}^{3} / \mathrm{s}\right)\end{array}$ & 15 & 15 & 17 \\
\hline & $\begin{array}{l}\text { Son süpürme } \\
\text { zamanı }(\mathrm{s})\end{array}$ & 20 & 20 & 20 \\
\hline \multirow{4}{*}{ 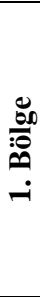 } & \begin{tabular}{|l|}
$\begin{array}{l}\text { İlerleme hızı } \\
(\mathrm{mm} / \mathrm{dk})\end{array}$ \\
\end{tabular} & 85 & 80 & 80 \\
\hline & Yüksek akım (A) & 42,3 & 44,5 & 43,6 \\
\hline & Düşük akım (A) & 19,1 & 20,0 & 19,6 \\
\hline & \begin{tabular}{|l|} 
Yüksek-düşük \\
akım zamanı(s)
\end{tabular} & 0,20 & 0,18 & 0,18 \\
\hline \multirow{4}{*}{ 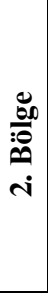 } & $\begin{array}{l}\text { İlerleme hızı } \\
(\mathrm{mm} / \mathrm{dk})\end{array}$ & 85 & 80 & 80 \\
\hline & Yüksek akım (A) & 40,7 & 42,7 & 41,8 \\
\hline & Düşük akım (A) & 18,3 & 19,2 & 18,8 \\
\hline & $\begin{array}{l}\text { Yüksek-düşük } \\
\text { akım zamanı(s) }\end{array}$ & 0,20 & 0,18 & 0,18 \\
\hline \multirow{4}{*}{ 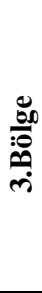 } & \begin{tabular}{|l|}
$\begin{array}{l}\text { İlerleme hızı } \\
(\mathrm{mm} / \mathrm{dk})\end{array}$ \\
\end{tabular} & 85 & 80 & 80 \\
\hline & Yüksek akım (A) & 43,2 & 45,4 & 42,1 \\
\hline & Düşük akım (A) & 19,4 & 20,4 & 19,1 \\
\hline & \begin{tabular}{|l|} 
Yüksek-düşük \\
akım zamanı(s)
\end{tabular} & 0,20 & 0,18 & 0,18 \\
\hline \multirow{4}{*}{$\begin{array}{l}\stackrel{80}{00} \\
\dot{0} \\
\dot{+0}\end{array}$} & \begin{tabular}{|l|}
$\begin{array}{l}\text { İlerleme hız1 } \\
(\mathrm{mm} / \mathrm{dk})\end{array}$ \\
\end{tabular} & 85 & 80 & 80 \\
\hline & Yüksek akım (A) & 41,5 & 44,1 & 43,2 \\
\hline & Düşük akım (A) & 18,7 & 20,0 & 19,6 \\
\hline & \begin{tabular}{|l|} 
Yüksek-düşük \\
akım zamanı (s)
\end{tabular} & 0,20 & 0,18 & 0,18 \\
\hline
\end{tabular}

\section{1. Çekme Testleri}

Kaynaklı numunelerin çekme testleri TS EN ISO 4136:2012 standardina uygun olarak gerçekleştirilmiştir. Test numuneleri kaynak yönüne dik gelecek konumda tel erozyon makinasıyla kesilmiştir. Testler sonucunda elde edilen dayanım değerleri Şekil 1'de gösterilmiştir. 
Orbital Tig Kaynak Yöntemiyle Kaynak Edilmiş Dubleks Paslanmaz Çeliklerin Mekanik, Metalurjik ve Korozyon Özellikleri

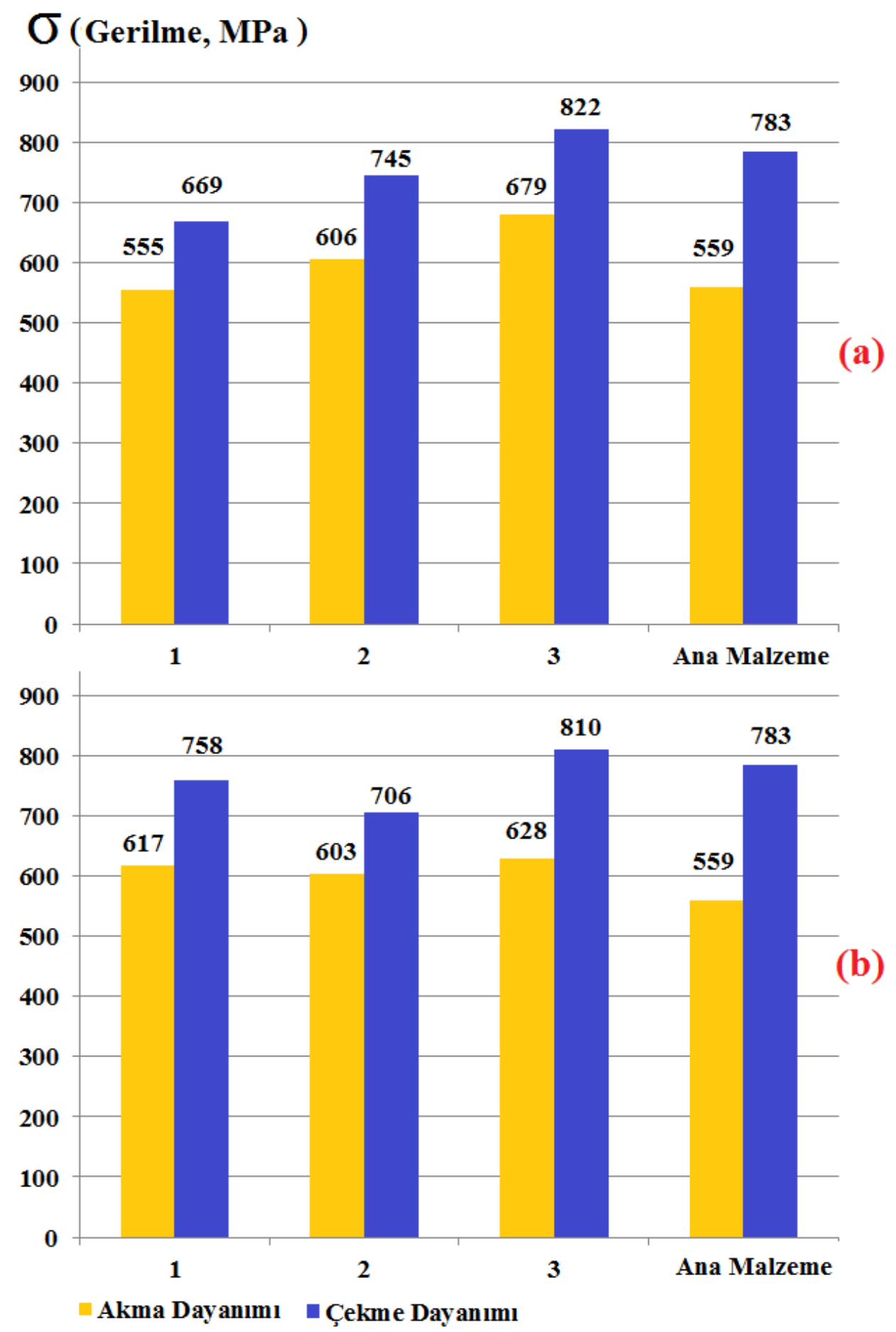

Şekil 1. 1, 2 ve 3 numunelerinin çekme değerleri a) WL b) WT 
Çekme testleri incelendiğinde, kaynaklı birleştirilmiş numunelere ait akma dayanımı değerlerinin ana malzemeninkinden yüksek olduğu görülmektedir. Çekme dayanımı değerlerinin ise ana malzemeye kiyasla 1 ve 2 no'lu numunelerde düşük, 3 no'lu numunelerde yüksek olduğu tespit edilmiştir. Ancak, tüm numunelerde yüzde uzama değerlerinin ana malzemeye kıyasla daha düşük (\%3-4 kadar) kaldığ1 görülmüştür. Tüm kaynaklı numuneler IEB'den kırılmıştır. Bu tespitlere göre kaynak işleminde ulaşılan yüksek tepe sıcaklığg 1 $\left(\sim 1350^{\circ} \mathrm{C}\right)$ ve yüksek soğuma hızlarına maruz kalan IEB'nin göreceli ferritik tane iriliği birlikte düşünüldüğünde, ferrit tane sınırlarında oluşması muhtemel intermetalik fazlar ve ferrit/ostenit dengesinin kaynaklı bağlantıların süneklik değerleri üzerinde kuvvetli olumsuz bir etki yarattığı değerlendirilmiştir.

İlave dolgu malzemesi kullanılmadan yapılan dubleks malzemelerin kaynağında ferrit/ostenit dengesi, akma ve çekme dayanımlarından ziyade süneklik değerleri üzerinde önemli bir etkiye sahiptir. Dubleks paslanmaz çeliklerin kaynağında artan ferrit içeriği sünekliği azaltmaktadır. Kaynaklı numunelere ait akma dayanımı değerlerinin ana malzemeden yüksek çıkması, yüksek ferrit içeriği ve düşük hacimsel yüzdeye sahip sigma ve chi fazlarının varlığı ile açıklanabilir.

\subsection{Mikroyapı İnceleme Sonuçları}

Kaynaklı parçalardan kalınlık kesiti boyunca hazırlanan numuneler, zımparalama ve parlatma işlemlerinin ardından Kalling's No:2 ve Beraha çözeltileri ile dağlanmıştır. Dağlanmış numunelerin kaynak metali ve isıdan etkilenmiş bölge (IEB) mikro yapıları değerlendirilmiştir. Şekil 2'de WL numunelerine ait mikro yap1 resimleri, Şekil 3'de WT numunelerine ait mikro yapı resimleri gösterilmiştir.

Dubleks paslanmaz çeliklerin kaynağında yapı tamamen ferritik katılaşma gösterir. Katılaşma süresince ostenit oluşumu gözlenmez. Fakat sıcaklık azaldıkça katı-katı dönüşümüyle ferrit fazından ostenit çökelir. Soğuma hızlarının IEB' ye nazaran daha yavaş olduğu kaynak metali ferrit taneleri içerisinde ve tane sınırlarında asiküler yapıda ve Widmänstatten plakaları halinde oluşan ostenit oranının fazla olduğu görülmektedir (Şekil $2 b-c$, Şekil 3b-d). Kaynak metalinin üst ve alt kısımlarında yeterli miktarda ostenit oluşumu gözlenmektedir (Şekil 3b). Bahse konu ostenit oluşumu oyuk korozyon dayanımı üzerinde olumlu etki meydana getirmektedir.

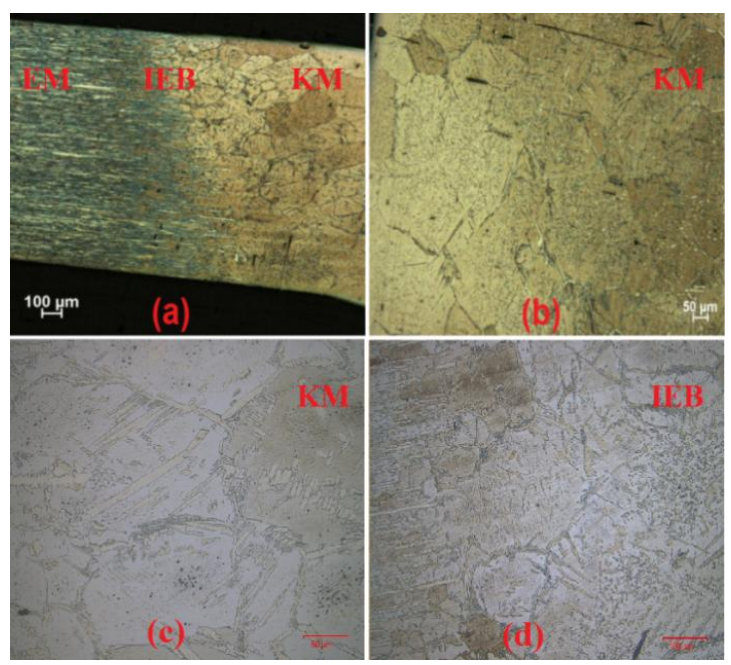

Şekil 2. WL 1-2-3 numunelerine ait mikroyap1 fotoğrafları

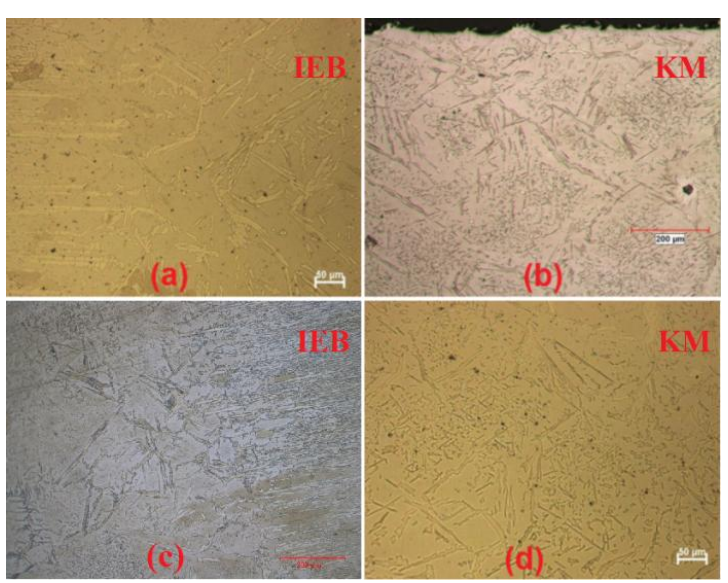

Şekil 3. WT 1-2-3 numunelerine ait mikroyap1 fotoğrafları

Tüm numunelerde IEB genişliğinin göreceli olarak birbirine yakın olduğu görülebilir. IEB' ye bitişik 
bölgede oluşan görece iri tanelerin, ostenitin yüksek sıcaklık altında çözünüp ferrite dönüşmesi neticesinde oluştuğu söylenebilir. IEB' de ferritik katılaşma esnasında meydana gelen tane büyümesine bağlı olarak ferrit miktarında artış ve ferrit tane sınırlarında ostenit oluşumu görülmektedir (Şekil 2d, Şekil 3c).

Tüm numunelerin kaynak metalinde ortalama tane büyüklükleri mikroyapı fotoğrafları kullanılarak 260 ile $300 \mu \mathrm{m}$ aralı̆̆ında bulunmuştur. Görece ferrit tane büyüklüğünün katılaşma esnasında yüksek ferrit içeriğine ve soğuma esnasında daha düşük ostenit oluşumuna neden olduğu değerlendirilmektedir. Tüm numunelerin KM ve IEB'lerinde ferrit/ostenit oranları İmage Proplus 6.0 görüntü analiz programı kullanılarak tespit edilmiştir. Tüm numunelerin KM ve IEB'lerinde ferrit miktarının ana malzemeye kıyasla biraz arttığı gözlenmektedir. Elde edilen değerler Çizelge 3'te verilmektedir.

Çizelge 3. Numunelerin ferrit/ostenit oranlarının gösterilmesi

\begin{tabular}{|c|c|c|}
\hline Numune adı & KM & IEB \\
\hline WL-1 & $\begin{array}{l}\% 65 \text { Ferrit } \\
\% 35 \text { Ostenit }\end{array}$ & $\begin{array}{l}\% 68 \text { Ferrit } \\
\% 32 \text { Ostenit }\end{array}$ \\
\hline WL-2 & $\begin{array}{l}\% 62 \text { Ferrit } \\
\% 38 \text { Ostenit }\end{array}$ & $\begin{array}{l}\% 66 \text { Ferrit } \\
\% 34 \text { Ostenit }\end{array}$ \\
\hline WL-3 & $\begin{array}{l}\% 66 \text { Ferrit } \\
\% 34 \text { Ostenit }\end{array}$ & $\begin{array}{l}\% 69 \text { Ferrit } \\
\% 31 \text { Ostenit }\end{array}$ \\
\hline WT-1 & $\begin{array}{l}\% 65 \text { Ferrit } \\
\% 35 \text { Ostenit }\end{array}$ & $\begin{array}{l}\% 70 \text { Ferrit } \\
\% 30 \text { Ostenit }\end{array}$ \\
\hline WT-2 & $\begin{array}{l}\% 67 \text { Ferrit } \\
\% 33 \text { Ostenit }\end{array}$ & $\begin{array}{l}\% 69 \text { Ferrit } \\
\% 31 \text { Ostenit }\end{array}$ \\
\hline WT-3 & $\begin{array}{l}\% 65 \text { Ferrit } \\
\% 35 \text { Ostenit }\end{array}$ & $\begin{array}{l}\% 68 \text { Ferrit } \\
\% 32 \text { Ostenit }\end{array}$ \\
\hline
\end{tabular}

\subsection{SEM-EDX Analiz Sonuçları}

Dubleks paslanmaz çeliklerin kimyasal kompozisyonunun yüksek mekanik özellikler ve korozyon dayanımını sağlaması açısından, kaynak işlemi gibi 1sıl işlemler sonucunda yapılarının eşit miktarda ostenit ve ferrit içermesi beklenmektedir. Ferrit ve ostenit içeriğinin belirlenebilmesi maksadıyla parlatılarak dağlanmış numunelerde ana metal ve kaynak metali kisimlarında ana alaşım elementleri olan demir, krom, nikel, molibden ve mangan içeriklerine ait EDX analizi yapılmıştır. Kimyasal kompozisyonu oluşturan alaşım elementleri ve miktarlarına ait değerler sırasıyla, Çizelge 4'de gösterilmektedir.

Çizelge 4. WL/WT 1-2-3 numunelerine ve ana malzemeye ait EDX sonuçlarının gösterimi

\begin{tabular}{|l|c|c|c|c|c|c|}
\hline $\begin{array}{l}\text { Analiz } \\
\text { Bölgeleri }\end{array}$ & \multicolumn{5}{|c|}{ Elementler (\%) } & $\begin{array}{c}\text { Numune } \\
\text { Adlar }\end{array}$ \\
\hline & $\mathrm{Cr}$ & $\mathrm{Ni}$ & $\mathrm{Mo}$ & $\mathrm{Fe}$ & $\mathrm{Mn}$ & \\
\hline $\begin{array}{l}\text { Ana } \\
\text { Malzeme }\end{array}$ & 20.66 & 4.66 & 2.59 & 60.91 & 1.62 & 2205 \\
\hline & 20.48 & 4.64 & 2.98 & 60.71 & 1.62 & WL-1 \\
& 20.86 & 4.85 & 3.04 & 60.69 & 1.51 & WT-1 \\
\cline { 2 - 7 } \\
Kaynak & 21.26 & 4.70 & 2.86 & 62.13 & 1.61 & WL-2 \\
Metali & 21.56 & 4.88 & 2.58 & 63.47 & 1.61 & WT-2 \\
\cline { 2 - 7 } & 20.89 & 4.64 & 2.85 & 61.03 & 1.65 & WL-3 \\
& 20.89 & 4.71 & 3.11 & 61.34 & 1.60 & WT-3 \\
\hline
\end{tabular}

EDX analizi sonucunda, tüm numunelerin kaynak metalindeki kimyasal kompozisyonlarının esas metale yakın olduğunu görülmektedir. $\mathrm{Cr}$ ve $\mathrm{Mo}$ (ferrit yapıc1) elementlerinin miktarları ana malzemeden yüksek, Ni (ostenit yapıcı) miktarının yüksek, Mn miktarının ise çok az düşük ve yakın olduğu belirlenmiştir. Kaynak metalindeki yüksek 1S1 girdisi ve soğuma hızına bağlı olarak ferrit miktarının daha yüksek olduğu bir ferrit/ostenit faz dağılımı oluştuğu söylenebilir.

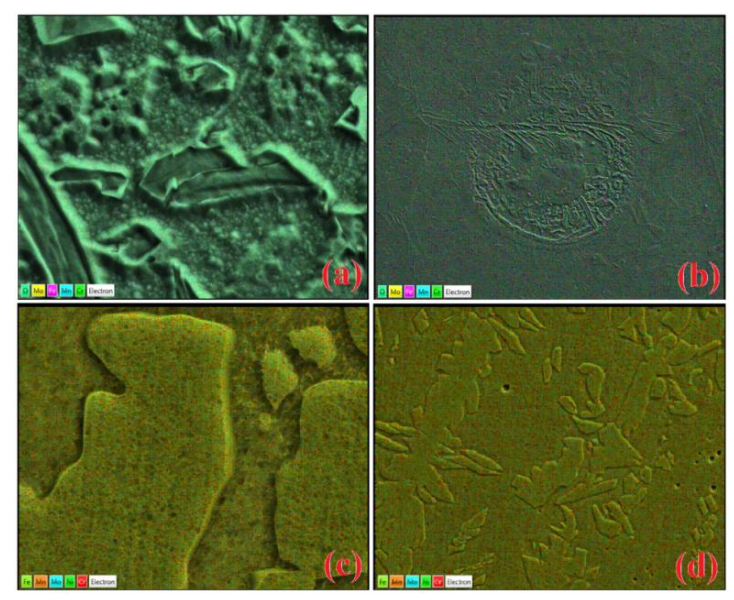

Şekil 4. a) WT-2, b) WT-1, c) WL-2 ve d) WL-3 numunelerinin $\mathrm{KM}$ ve IEB'lerine ait EDX sonuçları 
Tüm numunelerde ferrit tane sinırları ve ferrit tanelerinin içerisine doğru uzayıp büyüyen Widmänstatten plakalarının içerisinde, ostenit/ferrit ara yüzeyi ile ferrit taneleri içerisinde $\sigma$ ve $\lambda$ (chi) fazları ile $\mathrm{Cr}_{2} \mathrm{~N}$ varlığı SEM-EDX ve ikincil elektronlar kullanılarak incelenmiştir (Şekil 4). Fe-Cr-Mo içeriğine sahip $\sigma$ fazı ile aynı yapıda olan fakat daha yüksek Mo içeriğine sahip $\lambda$ (chi) fazı, krom nitrür ile karbür oluşumuna rastlanılmamıştır. Düşük tokluk değerlerine sebebiyet veren $\sigma$ ve $\lambda$ (chi) fazlarının tespit edilememesi gerçekten olmadığı anlamına gelmemelidir.

\subsection{Taneler Arası Korozyon Deneyi Sonuçları}

İleri derecede yükseltgen ortamlarda kullanılması düşünülen (örneğin nitrik asit ortamında) borulara Taneler arası korozyon deneyi (TS 3156 EN ISO 3651-1) uygulanır. Numuneler 120 mesh zımpara ile yüzeyleri ve kenarları zımparalanarak mekanik tufalı giderildikten sonra \% 65'lik nitrik asidin içerisinde 48 saatlik dönemler halinde 5 defa kaynatılmıştır.

Her dönem sonunda oluşan kütle kaybını belirlemek için hassas terazi kullanılmıştır. Nitrik asit çözeltisinin kimyasal reaksiyon etkileri, her deney periyodunun sonunda ve toplam deney süresinin sonunda ölçülen kütle kaybıyla belirlenmiştir. Kütle kaybı belirlenirken her defasında cihaz kalibre edilmiş, her ölçüm 5'er defa yapılmış ve standart sapma göz önüne alınarak ortalama değerleri hesap edilmiştir. Deney dönemlerindeki korozyon hızı ve deney sonubaşlangıç ağırlıklarına göre korozyon hızları Çizelge 5'de yer almaktadır.

Korozyon deneyi sonuçları incelendiğinde, elde edilen korozyon hızları, KM ve IEB' de kaynak işlemi sonucunda nitrik asit içerisinde taneler arası korozyona karşı hassasiyeti oluşturan krom karbürlerin ve nitrürlerin çökelmesi, sigma fazı gibi metaller arası bileşiklerin çökelmesi veya safsızlık elementlerinin tane sınırlarında ayrışması durumlarının yoğun/aşırı olmadığını göstermektedir.
Çizelge 5. Numunelerin deney dönemlerindeki korozyon hizı

\begin{tabular}{|c|c|c|c|c|c|c|}
\hline \multirow{2}{*}{ : } & \multicolumn{6}{|c|}{ Numunelerin korozyon hızı $\left(\mathrm{mm}^{-\mathrm{a}^{-1}}\right)$} \\
\hline & WL-1 & WL-2 & WL-3 & WT-1 & WT-2 & WT-3 \\
\hline 1 & 0,0010 & 0,0007 & 0,0009 & 0,0008 & 0,0009 & 0,0029 \\
\hline 2 & 0,0071 & 0,0005 & 0,0008 & 0,0007 & 0,0006 & 0,0059 \\
\hline 3 & 0,0010 & 0,0008 & 0,0012 & 0,0014 & 0,0015 & 0,0082 \\
\hline 4 & 0,0012 & 0,0013 & 0,0015 & 0,0021 & 0,0017 & 0,0036 \\
\hline 5 & 0,0017 & 0,0018 & 0,0017 & 0,0036 & 0,0012 & 0,0028 \\
\hline
\end{tabular}

\subsection{Oyuk Korozyon Deneyi Sonuçları}

Oyuk korozyon deneyi oksitleyici klor içeren ortamlara maruz kalan paslanmaz çeliklerin oyuk korozyonuna dayanımını belirlemek maksadıyla kullanılır. Oyuk korozyon deneyi ASTM G48-11 (Demir Klorür Çözeltisi İçerisinde Paslanmaz Çeliklerin Oyuk Ve Aralık Korozyon Dayanımının Belirlenmesi Standart Testi) standard1 esas alınarak gerçekleştirilmiştir. Standardın Metod ADemir klorür Oyuk Testi ve Metod E-Paslanmaz Çelikler İçin Kritik Oyuk Sıcaklığı Testi kısımları uygulanmıştır. Metod-A için hazırlanan korozif çözeltinin kimyasal reaksiyon etkileri, her deney periyodunun sonunda ölçülen kütle kaybıyla belirlenmiştir. Kütle kaybı belirlenirken her defasında cihaz kalibre edilmiş, her ölçüm 5'er defa yapılmış ve standart sapma göz önüne alınarak ortalama değerleri hesap edilmiştir. Başlangıç ile deney dönemi (24 saat) sonunda elde edilen kütle değerleri esas alarak hesaplanan korozyon hızı değerleri tüm numuneler için 0,0001 $\mathrm{g} / \mathrm{cm}^{2}$ 'dir.

Optik mikroskop kullanılarak tüm numunelerden makro ile mikro görüntüler alınmıştır. $\mathrm{Bu}$ görüntüler Şekil 5'de gösterilmektedir. İncelenen görüntülerde oyuklara rastlanılmamıştır. 


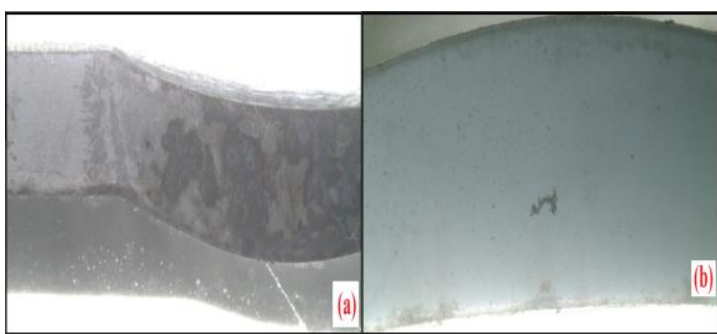

Şekil 5. a) WL-2 numunesine ait makroyap1 fotoğrafı (30x) dağlanmış, b) WT-3 numunesine ait makroyapı fotoğrafi (30x) parlatılmış

Metod-E testi uygulanmadan önce ana malzemenin kritik oyuk sıcaklığ $40^{\circ} \mathrm{C}$ olarak hesaplanmıştır. Dubleks malzemelerin dolgu teli kullanılmadan yapılan kaynağında, kaynak bölgesinin kritik oyuk sıcaklığının ana malzemeden düşük kalması beklenmelidir. Metod-E testi sonucunda oluşan oyukların derinlikleri iğne uçlu komparatör yardımıyla ölçülmüştür. Ölçülen ortalama ve en yüksek derinlik değerleri Çizelge 6'da yer almaktadır.

Çizelge 6. Numunelere ait derinlik ölçümleri

\begin{tabular}{|c|c|c|}
\hline $\begin{array}{c}\text { Numune } \\
\text { Adı }\end{array}$ & $\begin{array}{c}\text { Ortalama } \\
\text { Derinlik (mm) }\end{array}$ & $\begin{array}{c}\text { Maksimum } \\
\text { Derinlik (mm) }\end{array}$ \\
\hline WL-1 & 0,042 & 0,060 \\
\hline WL-2 & 0,041 & 0,055 \\
\hline WL-3 & 0,045 & 0,054 \\
\hline WT-1 & 0,047 & 0,058 \\
\hline WT-2 & 0,044 & 0,065 \\
\hline WT-3 & 0,042 & 0,067 \\
\hline
\end{tabular}

Çizelge 6 incelediğinde standardın öngördüğü $0.025 \mathrm{~mm}$ değerinden yüksek değerler olduğu görülmektedir. Optik mikroskop kullanılarak tüm numunelerden oyuk oluşumlarını içeren görüntüler alınmıştır. $\mathrm{Bu}$ görüntüler Şekil 6'da gösterilmektedir. $\mathrm{Bu}$ durum esas alınarak kritik oyuk sıcaklığının tüm numuneler için $27^{\circ} \mathrm{C} \pm 1$ olduğu söyleyebilir.

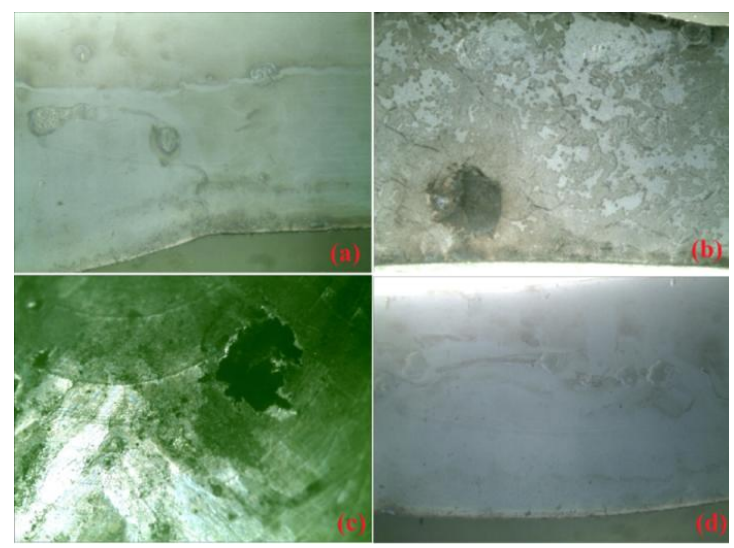

Şekil 6. a) WL-1 numunesine ait mikroyap1 fotoğrafi $(50 \mathrm{x}), \mathrm{b}) \mathrm{WT}-1$ numunesine ait mikroyap1 fotoğrafi $(60 \mathrm{x}), \mathrm{c})$ WT-3 numunesine ait makroyapı fotoğrafi (40x), d) WL-3 numunesine ait mikroyap1 fotoğrafi $(50 x)$

\section{SONUÇLAR}

$\mathrm{Bu}$ çalışmada Orbital TIG kaynak yöntemiyle birleştirilmiş dubleks paslanmaz çelik boruların mekanik, mikroyapı ve korozyon özellikleri konusu araştırılmıştır. Elde edilen sonuçlar aşağıda verilmiştir:

- SEM-EDX analizi sonucunda, tüm numunelerin kaynak metalindeki kimyasal kompozisyonlarının esas metale yakın olduğunu görülmüştür. Tüm numunelerde intermetalik faz, krom nitrür ve krom karbür oluşumlarına rastlanılmamıştır. $\mathrm{Bu}$ oluşumlara rastlanılmaması olmadıkları anlamina gelmemelidir.

- Tüm numuneler IEB' den kopmuştur. Tüm numunelerde, EM' in uzama değerlerine (\%30) kıyasla çok düşük uzama değerleri (\% 3-4 kadar) elde edilmiştir. WL20 ve WT40 elektrod ile kaynak edilen numunelerin akma ve kopma dayanımlarının ASTM'nin minimum değerlerini fazlasıyla karşıladığı görülmektedir.

- Mikroyapı fotoğraflarına baktığımızda; tüm numunelerde kaynak metali içerisinde, ferrit 
tane sinırlarında ostenit oluşumu, Widmänstaten ostenit plakalarının oluşumu ve ferrit taneleri içerisinde ostenit oluşumu görülmektedir. Tane sinırlarında ve tane içerisinde zengin ostenit oluşumu difüzyon süresinin yeterli olduğunu göstermektedir. Dubleks paslanmaz çeliklerin kaynağında bu oluşumlar tipik olarak görülür.

- Taneler arası korozyon deneyi sonuçlarını incelediğimizde; orbital GTAW kaynak yöntemi ile birleştirilen dubleks paslanmaz çelik borulardan hazırlanan tüm numunelerin standart tasarım ve kullanım kriterleri açısından yeterli taneler arası korozyon dayanımını sağladıkları tespit edilmiştir.

- Oyuk korozyon deneyi sonuçların incelediğimizde; tüm numunelerin standardın gerektirdiği oyuk korozyon dayanımını sağladıkları ve $27 \pm 1^{\circ} \mathrm{C}$ CPT (kritik oyuk sıcaklık değeri) değerlerine sahip oldukları belirlenmiştir.

\section{KAYNAKLAR}

1. Kisasöz, A., Karaaslan, A., 2012. Dubleks Paslanmaz Çeliklerde Oluşan Yüksek Sicaklık Fazlarına Genel Bir Bakış, Teknik Yazı, Türk Mühendis ve Mimar Odaları Birliği Metalurji Mühendisleri Odası, 7(162), 57-61s.

2. Nowacki, J., Lukojc, A., 2005. Structure and Properties of the Heat-Affected Zone of Duplex Steels Welded Joints, Journal of Materials Processing Technology, 164-165, pp. 1074-1081.

3. Karlsson, L., 1999. Review, Intermetallic Phase Precipitation in Duplex Stainless Steels and Weld Metals-metallurgy, İnfluence on Properties, Welding and Testing Aspects, Welding in the World, vol. 43, no. 5, pp. 20-41.

4. Ogawa, T., Koseki, T., 1989. Effect of Composition Profiles on Metallurgy and Corrosion Behavior of Duplex Stainless Steel Weld Metals, Welding Journal 68, pp. 181-191.

5. Kaluç, E., Taban, E., 2007. Paslanmaz Çelikler, Geliştirilen Yeni Türleri ve Kaynak edilebilirlikleri, TMMOB, İstanbul.
6. Lippold, J.C. Kotecki, D.J., 2005. Welding Metallurgy and Weldability of Stainless Steels, John Wiley and Sons, New Jersey, USA.

7. Wilsdorf, R. Pistor, R., Sixsmith, J.J. Jin, H., 2006. Welding Aluminum Pipe And Tube With Variable Polarity, Welding Journal, Vol. 85, no. 4, pp. 42-43.

8. Emmerson, J., 2000. Orbital Narrow Gap MCW Pipe Welding, Welding\&Metal Fabrication, vol. 68, no. 8, pp. 9-11.

9. Benway, E.A., 2000. Advancements in Automatic Orbital Welding Expand Its Use, Provide Welders With More Option, Industrial Maintenance \& Plant Operation, vol. 61, no. 7, pp. 22.

10. Latifi, H., 2012. Advanced Orbital Pipe Welding, Ms thesis, Lappeenranta University of Technology, Finland.

11. Harris, I.D., 2011. Welding Advances in Tube And Pipe Applications, Welding Journal, vol. 90, no. 6, pp. 58-63.

12. Benway, E.A., 2009. What To Look For in Orbital Welding Training Programs, Penton's Welding Magazine, vol. 82, no. 5, pp. 18-22.

13. POLYSOUDE, Orbital Welding Handbook, http://www.polysoude.com/orbital-welding (erişim tarihi 12 Haziran 2015). 
